\title{
Working conditions, health and productivity among dentists in Swedish public dental care - a prospective study during a 5-year period of rationalisation
}

Bo Rolander, Dirk Jonker, J Winkel, L Sandsjo, I Balogh, Erland Svensson and Kerstin Ekberg

\author{
Linköping University Post Print
}

\section{Tweet}

N.B.: When citing this work, cite the original article.

This is an electronic version of an article published in:

Bo Rolander, Dirk Jonker, J Winkel, L Sandsjo, I Balogh, Erland Svensson and Kerstin Ekberg, Working conditions, health and productivity among dentists in Swedish public dental care - a prospective study during a 5-year period of rationalisation, 2013, Ergonomics, (56), 9, 1376-1386.

Ergonomics is available online at informaworldTM:

http://dx.doi.org/10.1080/00140139.2013.817613

Copyright: Taylor \& Francis: STM, Behavioural Science and Public Health Titles http://www.tandf.co.uk/journals/default.asp

Postprint available at: Linköping University Electronic Press

http://urn.kb.se/resolve?urn=urn:nbn:se:liu:diva-100320 


\section{Working conditions, health and productivity among dentists in Swedish public dental care \\ - a prospective study during a 5-year period of rationalisation}

Rolander $\mathrm{B}^{1,2}$; Jonker $\mathrm{D}^{1,2}$; Winkel J ${ }^{3,8}$; Sandsjö L ${ }^{4}$; Balogh $\mathrm{I}^{5}$; Svensson $\mathrm{E}^{7}$; Ekberg $\mathrm{K}^{1,6}$.

${ }^{1}$ National Centre for Work and Rehabilitation, Department of Health and Medicine, Linkoping University.

${ }^{2}$ Futurum, Department of Health and Care, Jönköping, Sweden.

${ }^{3}$ Department of Sociology and Work Science, University of Gothenburg, Sweden

${ }^{4}$ MedTech West/School of Engineering, University of Borås, Borås, Sweden.

${ }^{5}$ Department of Occupational and Environmental Medicine, Lund University, Sweden

${ }^{6}$ HELIX Vinn Excellence Centre, Linköping University, Sweden

${ }^{7}$ Department of Computer Science, Linköping University, Sweden

${ }^{8}$ Department of Management Engineering, Technical University of Denmark, Denmark

Corresponding author:

Bo Rolander, MScPT, PhD.

Futurum Department of Health and Care

Ryhov County Hospital

SE-551 85 Jönköping, Sweden

E-mail: bo.rolander@lj.se

Tel +46 36322839 


\section{Abstract}

In recent decades, comprehensive rationalisations have been implemented in public dentistry in Sweden. How rationalisations affect working conditions, health and production from a long-term perspective has been poorly investigated. The present study aims to analyse changes and associations in dentists' working conditions, health and productivity during a 5year period.

In 2003 and 2008, sixty-five dentists responded to questionnaires measuring work conditions and health. Treatment times for patients and productivity were tracked in electronic registers.

Paired t-tests showed that the number of treated adult patients per dentist increased and perceived physical working conditions improved while perceived work control and leadership deteriorated. Structural equation modelling showed that physical factors were important for health and productivity.

Conclusions: When assessing risks in the work environment, there is a need to understand the interaction of effects on working conditions and health due to rationalisations so as to increase the sustainability of production systems.

\section{Practioner Summary}

Dentistry in Sweden has undergone considerable change. Questionnaire surveys with dentists, undertaken in 2003 and 2008, found that the present rationalisations resulted in improved perceived physical working conditions. Aspects of the psychosocial working environment had deteriorated, however. This is a concern as health and workability are important for workplace efficiency.

Keywords: Physical working conditions; Production, Organisational sustainability, leadership, work control. 


\section{Introduction}

Dentists report a high prevalence of work-related musculoskeletal disorders (Akesson et al. 1999, Alexopoulos et al. 2004, Leggat et al. 2007). Several studies show that dentistry is physically (Akesson et al. 1997, Finsen et al. 1998, Rolander et al. 2005a, Rolander et al. 2005b, Jonker et al. 2009) and psychosocially demanding (Bejerot 1998, Hjalmers et al. 2006, Rolander et al. 2008).

Dentistry in Sweden is an area of the public sector that went through comprehensive rationalisations early on (Winkel \& Westgaard 1996). Rationalisation is defined as “... the methods of technique and of organisation designed to secure the minimum waste of either effort or material ...” (cf. World Economic Conference in Geneva, 1927 cited and further explained by Westgaard and Winkel, 2011). The field of dentistry has been influenced by several rationalisation strategies since the 1950s when early initiatives applied Tayloristic concepts (Bjorkman 1996). In the most recent two decades, new public management and lean production ideas have been implemented in Swedish dentistry (Harrisson et al. 1990, Hasselbladh 2001, Brödner and Forslin 2002, Almqvist 2006). Rationalisations may involve changed demands on how leadership is executed (Vest and Gamm 2009) and the rearrangement of work procedures and work tasks, and often seem to imply work intensification through changed temporal exposure factors (Forsman et al. 2002, Kazmierczak et al. 2005, Ostensvik et al. 2008, Palmerud et al. 2012, Westgaard and Winkel 2011, Jonker et al. 2011, Jonker et al, 2013).

A recent review has documented the mostly negative effects of rationalisation on musculoskeletal and mental health and the corresponding risk factors, - in particular within the healthcare sector (Westgaard and Winkel 2011). Within this sector the Swedish public dental health care system seems to have gone through a particular negative development regarding these working environment issues (e.g. Winkel and Westgaard 1996). A 
contributing reason to this may be the more dramatic changes in management control systems towards the 'hard' version of Human Resource Management compared with other academicians as shown by Bejerot et al. (1998, 1999). In particular, they demonstrated increased performance and monitoring of results and competition as a means of increasing production (Bejerot et al. 1998). However, other studies also show that rationalisation, particularly in industry, may occur without impairment and even with improvements in both the psychosocial and physical working environment (for references, see Westgaard and Winkel 2011).

The possible complex interplay between rationalisations and working conditions on health and productivity has been outlined in a model by Winkel and Westgaard (1996). In a slightly modified version of this model (Figure 1), it was assumed that rationalisation might have direct effects on physical and psychosocial working conditions, and working conditions might have direct effects on aspects of health. Physical and psychosocial working conditions and aspects of health were assumed to have direct effects on productivity. It was also assumed that aspects of health might be a mediating ${ }^{1}$ variable between working conditions and productivity. Based on this hypothetical model and previous research, it was expected that rationalisation designed to increase productivity might affect working conditions negatively among dentists, which might lead to negative effects on musculoskeletal disorders and/or stress symptoms and thereby limiting effects of rationalisation on productivity.

\footnotetext{
${ }^{1}$ The simplest example of mediation is a three-variable recursive model which provides two causal paths feeding into a single dependent variable; the independent variable and the mediating variable directly affect the dependent variable, while the independent variable directly affects the mediator
} 


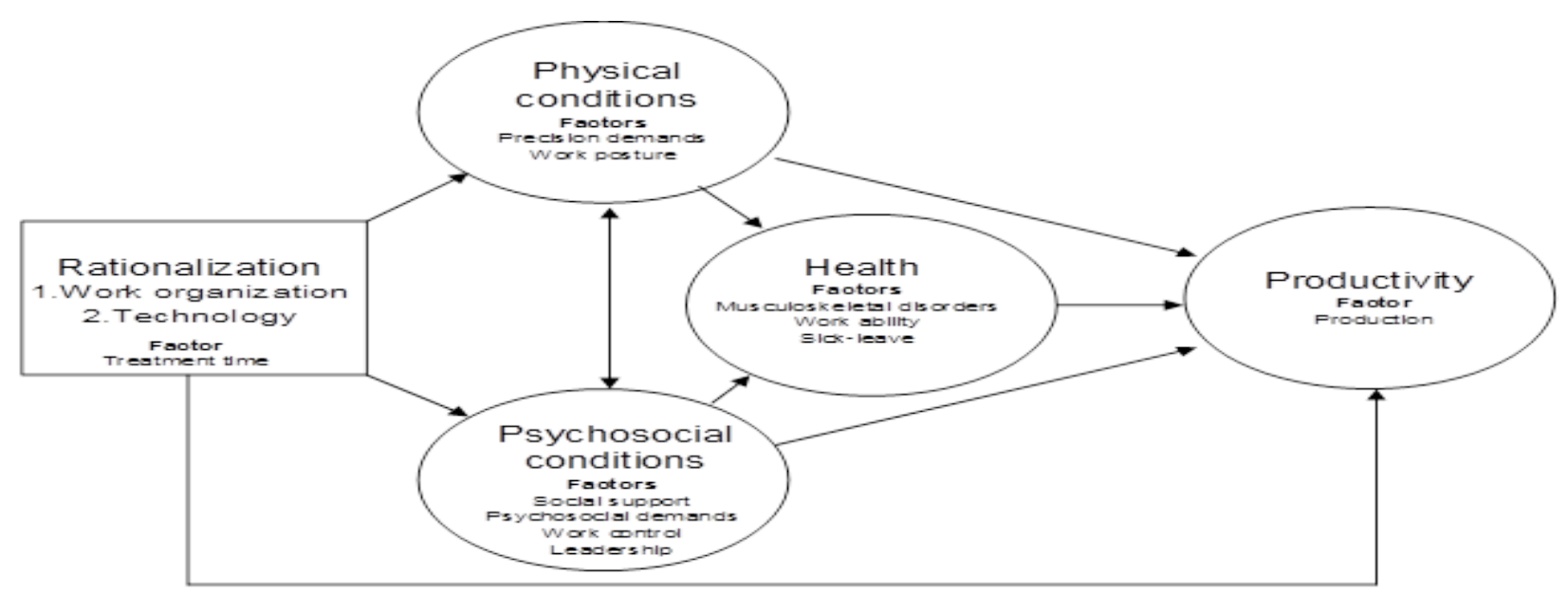

Figure1. Model on which the hypothesis of the present investigation is based (Modified from Winkel and Westgaard, 1996) with the factors in this study which corresponds to the model's headlines. See chapter 2.5.

Based on this background, the present study poses two main research questions: Does a 5-year period of rationalisation in public Swedish dental care:

1. Increase productivity and impair psychosocial and physical working conditions?

2. Change the association patterns between the variables outlined in the above mentioned model? (Figure 1)

\section{Material and Methods}

\subsection{Research setting.}

The public dental economy in Sweden was problematic at the beginning of the 2000s and there was a need to recruit dentists as public dentistry could not fulfill commitments within the framework of the welfare system. Rationalisations were implemented in the public system to cope with the dental crisis by making dentists’ work more effective. Dental care provided by Jönköping County Council in Sweden was reorganised into smaller units with economic control, some work tasks were transferred between clinics to improve access for patients through longer opening hours, and some units were downsized. The staff was offered competence development training and technology was improved (Munvädret 2003:3). Information technology is an important feature of rationalisation and in dentistry may be a 
tool for the dentists when planning patient treatment. Information technology may also involve management work control of employees (Bejerot et al. 1998). In public dentistry, rationalisation also involved the transfer of some of the dentists' tasks to dental hygienists and dental nurses. The goal was to achieve a more efficient mix of tasks and more interaction between professional groups to improve the utilisation of skills and thus the efficiency of the work organisation (SOU 2002).

During the period studied, 2003-2008, the following organisational and technological changes were implemented in public dental care (Figure 2).

\section{Organisational changes.}

- Reorganisation into smaller units that bore their own costs and the introduction of one more management level in the organisation. Some clinics were downsized and activities were merged with other clinics.

- Monthly economic feedback per unit and tighter financial management from the central office.

- Delegation of some tasks from dentists to other professions with lower salaries and shorter education. Delegation was to be consistent with the good and safe care of patients and did not include diagnosis, treatment planning, dental or medical tasks.

- A salary revision program leading to increased salaries for dentists, taking them from below the national average to slightly above.

\section{Technological changes}

- Introduction of digital X-rays allowing dentists to assess X-rays from a PC instead of having to go to another room with a light board. 
- $\quad$ SMS text message reminders to patients to reduce the number of missed appointments.

- A new IT-system to enable online communication between healthcare providers and insurance funds, in order to speed up the estimate of costs for the patient and then effectively plan treatment.

- Self-service by patients on a screen upon arrival at the clinic, informing the dentist immediately that the patient had arrived.

Information was obtained from dentistry documents (Munvädret 2003:2, Munvädret 2009:3) and interviews with dentists.

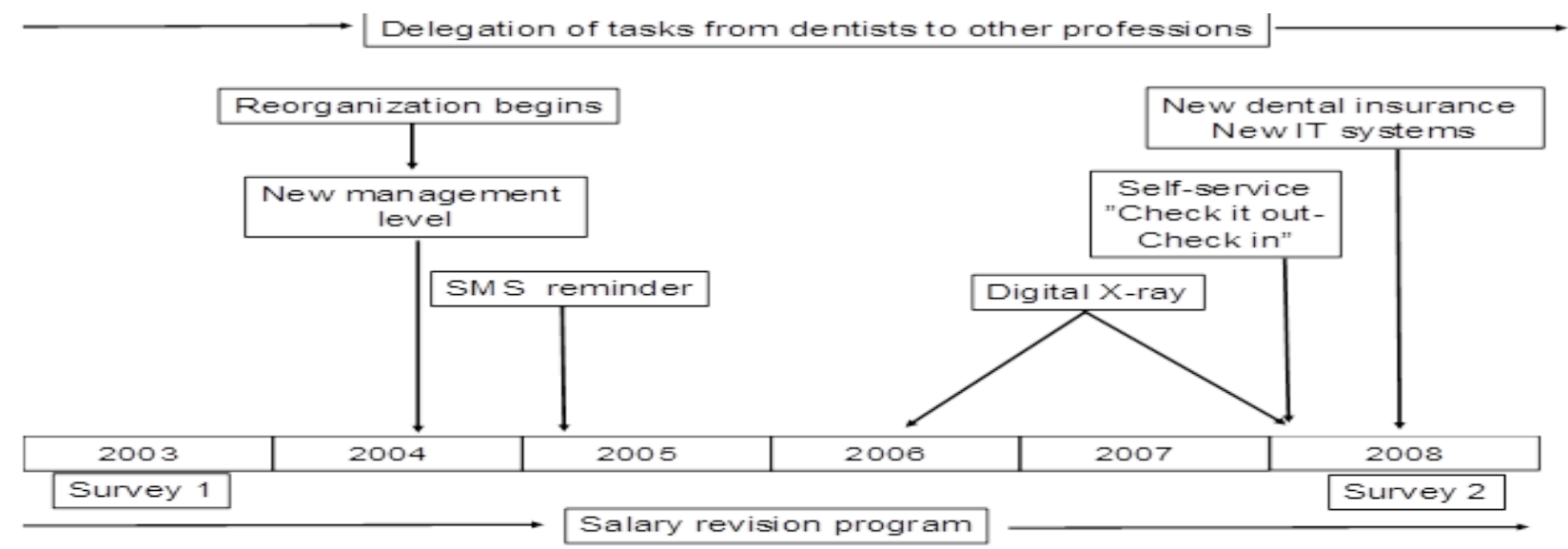

Figure 2. Time schedule of the questionnaire surveys, salary revision program and individual rationalization actions in the present investigation.

\subsection{Study design}

The study is a prospective cohort study. Dentists working in public dental care responded to a web-based questionnaire in 2003 and 2008. Production data was retrieved from the electronic patient register during the same period. Changes in exposure and outcome measures during the study period were estimated by comparing measures assessed in 2003 and 2008 . Effects of the organisational and technological changes were estimated by comparing association patterns between the measures in 2003 and 2008. 


\subsubsection{Participants and data collection}

All dentists employed by Jönköping County Council were invited to respond to the webbased questionnaire. A total of 152 dentists were employed in 2003, 121 dentists (80\%) responded. In 2008, 155 dentists were employed and 114 dentists (74\%) responded to the questionnaire. In all, 65 dentists, 52\% women and 48\% men, responded to both questionnaires and constitute the cohort in this study. In 2003, the average age was 49 years (sd \pm 9.5 ), and the average employment time was 18 years (sd \pm 11$)$. On average, they worked 38 hours $(\mathrm{sd} \pm 3)$ per week in 2003 and 37 hours per week (sd \pm 6$)$ in 2008.

The questionnaires were distributed in September 2003 and September 2008 (see Figure 2) and comprised items on demographic data, physical and psychosocial working conditions, leadership, health and work ability.

\subsubsection{Drop-out analyses from baseline to follow-up}

Among the 121 dentists who responded to the survey in 2003, 56 dentists (46\%) did not respond in 2008. The reasons for non-response were: retirement $(n=11)$, long-term sick-leave $(n=2)$, change of professional role (e.g. to educational), having left the organisation $(n=28)$, having moved abroad $(n=3)$, deceased $(n=2)$. Ten gave no reason for not responding. There were no significant differences between the cohort of 65 dentists and the 56 dentists who dropped out with regard to average age and employment time in 2003.

\subsection{Outcome measures}

\subsubsection{Productivity}

Treatment time was used as one estimate of productivity. It was assessed as the time assigned per adult or child patient in the electronic patient register, T4, for years 2003 and 
2008. This is the system that dentists use to record working hours, holidays, cost to the patient, information from social insurance, X-ray images and patient records. The standard treatment time for adults is 30 minutes and for children 20 minutes. A dentist may deviate from the standard treatment time if necessary by changing it by 10-minute intervals. This measure was used as "treatment time". Productivity was also assessed as the number of treated patients per dentist per year.

\subsubsection{Health and work ability}

The questionnaire comprised nine items measuring musculoskeletal disorders based on a modified version of the Nordic Questionnaire (Kuorinka et al. 1987) and nine items measuring pain intensity with a response scale that contained eleven response options, the anchor points were defined as 'no inconvenience' and 'severe inconvenience'. Two items measured sick-leave, defined as absence due to sickness during the last six months, with response options ranging from 'less than a week' to 'more than 2 months'. Four items measuring work ability were taken from the Work Ability Index (Tuomi et al. 1998). The items concerning muscular disorders, pain intensity and work ability had different response scales and were transformed to $\mathrm{z}$ scores with a mean of 0.0 and an SD of 1.0 to allow for comparisons (Byrne 2001). Since no factor structures for these items were available from previous studies, an exploratory factor analysis was conducted on 28 items (including four items from leadership, see 2.4.4) based on 114 dentists who answered the questionnaire in 2008. Principal Component Analysis with direct oblimin rotation extracted three factors labelled: work ability, musculoskeletal disorders and sick-leave. The explained variance was 58\%. Kaiser-Meyer-Olkin and Bartlett's Test showed a p-value less than 0.5. Two items concerning the presence of sickness, seven items on musculoskeletal disorders and eight items concerning pain intensity did not fit into the factor structure and were excluded in the 
analysis. The remaining two items for musculoskeletal disorders and one item for pain intensity precipitated the same factor in the analysis and were labelled "Musculoskeletal disorders”.

\subsubsection{Physical working conditions}

Physical working conditions were assessed by 9 items describing the perception of demands on concentration, repetitive movements, accuracy, vision, monotonous and uncomfortable positions and heavy lifting (Ekberg et al. 1994) and the response scale had eleven response alternatives. The anchor points were defined by positive and negative assertions. These item scores were averaged in the following two factors: precision demands and work posture, according to an exploratory factor analysis in an earlier study (Rolander and Bellner 2001).

\subsubsection{Psychosocial working conditions}

Psychosocial working conditions were assessed by 46 items describing social support, work pace and stress, the possibility to influence work organisation and to make own decisions, variety in work, leadership, career opportunities, changes in the workplace and the possibility of personal development (Ekberg et al. 1994). The response scales had eleven response alternatives. The anchor points were defined by positive and negative assertions. The 46 items were structured into the following three factors: psychosocial demands, social support and work control, according to an exploratory factor analysis in an earlier study (Rolander and Bellner 2001). Since no factor structures for leadership (four items) were available from previous studies, an exploratory factor analysis was conducted based on 114 dentists who answered the questionnaire in 2008 (the same factor analysis as in Chapter 2.4.2: 'Health and Work ability') 


\subsection{Applicability of the questionnaire regarding exposure and health}

The degree of construct validity, reliability and general applicability of the factors was assessed by a confirmative factor analysis of all working conditions factors, and health and work ability factors (Table 1).

The confirmative analysis was performed on a group of 170 dentists who only answered the questionnaire either in $2003(n=56)$ or in $2008(n=49)$ and the responses received in 2008 $(n=65)$ from the dentists who are included in the cohort. A confirmatory factor analysis requires a group other than the one used for the explorative factor analyses. This group of 170 was assessed as fulfilling this requirement. The factor model fit, evaluated by means of Root Mean Square of Approximation (RMSEA), was 0.04. The Comparative Fit Index (CFI) was 0.91 (a CFI $>0.90$ equals a good fit), the Root Mean Square Residual $(\mathrm{RMR})=0.07$. An RMR of zero indicates a perfect fit. All values indicate that the fit of the factor model is good and the results confirmed the six working condition factors and three health factors. Accordingly, the factor structure is independent of sample and can be generalised at least to public sector dentists in Sweden. The factor-reliability was tested with Cronbach's Alpha and showed good factor reliability (Table 1). 
Table 1. Items, factor loadings, factors from confirmatory factor analysis and Chronbach's Alpha (n=170).

\begin{tabular}{|c|c|c|c|}
\hline & $\begin{array}{l}\text { Factor } \\
\text { loadings }\end{array}$ & Factor & $\begin{array}{l}\text { Chronbach's } \\
\text { Alpha }\end{array}$ \\
\hline $\begin{array}{l}\text { Does your work normally demand a high degree of physical concentration } \\
\text { during long periods of time? }\end{array}$ & 0.82 & $\begin{array}{l}\text { Precision } \\
\text { demands }\end{array}$ & $\mathbf{0 . 9 0}$ \\
\hline Does your work normally require a high degree of accuracy? & 0.90 & & \\
\hline Dos your work normally include tasks which require good vision? & 0.87 & & \\
\hline Are repetitive movements common in your work? & 0.56 & Work posture & 0.76 \\
\hline Are monotonous or immobile working positions common in your work? & 0.69 & & \\
\hline Are uncomfortable working positions common in your work? & 0.95 & & \\
\hline Do you feel that you have a fairly pleasant working team? & 0.49 & Social support & 0.77 \\
\hline How do you perceive the co-operation with your fellow workers? & 0.50 & & \\
\hline $\begin{array}{l}\text { When work issues come up where you have different opinions, do you take } \\
\text { them up for general discussion at your workplace? }\end{array}$ & 0.74 & & \\
\hline $\begin{array}{l}\text { Do your fellow workers assist you if you happen to be overloaded with } \\
\text { work? }\end{array}$ & 0.66 & & \\
\hline $\begin{array}{l}\text { Do you have any colleague to talk with when things have been difficult or } \\
\text { strenuous at work? }\end{array}$ & 0.79 & & \\
\hline Is your psychosocial work load too high? & 0.72 & Psychosocial & 0.81 \\
\hline Do you work at maximum capacity? & 0.83 & demands & \\
\hline $\begin{array}{l}\text { Is the strain in your job so high that you hardly talk or think about anything } \\
\text { except work? }\end{array}$ & 0.66 & & \\
\hline Is the strain in your job so high that you risk making errors or mistakes? & 0.43 & & \\
\hline $\begin{array}{l}\text { Does your work often demand maximum concentration for considerable } \\
\text { periods of time? }\end{array}$ & 0.65 & & \\
\hline Is a high working pace standard in your work? & 0.43 & & \\
\hline Can you influence the organisation and performance of your work? & 0.86 & Work control & 0.79 \\
\hline Can you yourself influence the working pace at any way? & 0.73 & & \\
\hline $\begin{array}{l}\text { Can you in any way influence which work assignments you should } \\
\text { perform? }\end{array}$ & 0.67 & & \\
\hline $\begin{array}{l}\text { Are you free to make your own decisions concerning changes / } \\
\text { improvements in your work? }\end{array}$ & 0.63 & & \\
\hline How is the contact and the cooperation with your nearest superior? & 0.98 & Leadership & 0.77 \\
\hline $\begin{array}{l}\text { Does your nearest superior usually show appreciation when you do a good } \\
\text { job? }\end{array}$ & 0.87 & & \\
\hline Does one listen to proposals on changes in your work? & 0.54 & & \\
\hline $\begin{array}{l}\text { How do you assess your current work ability in relation to the physical } \\
\text { work demands your work require? }\end{array}$ & 0.83 & Work ability & 0.72 \\
\hline $\begin{array}{l}\text { How do you assess your current work ability in relation to the psychosocial } \\
\text { work demands your work require? }\end{array}$ & 0.76 & & \\
\hline $\begin{array}{l}\text { With regard to your health - do you believe that you can work in your } \\
\text { present profession in about two years? }\end{array}$ & 0.47 & & \\
\hline $\begin{array}{l}\text { If you consider whatever has to do with your work satisfaction and work } \\
\text { environment, how pleased would you say that you are? }\end{array}$ & 0.53 & & \\
\hline $\begin{array}{l}\text { Did you have inconveniences (pain, discomforts) some time during the last } \\
12 \text { months from neck? }\end{array}$ & 0.56 & $\begin{array}{l}\text { Musculoskeletal } \\
\text { disorders }\end{array}$ & 0.66 \\
\hline $\begin{array}{l}\text { Did you have inconveniences (pain, discomforts) some time during the last } \\
12 \text { months from shoulders? }\end{array}$ & 0.63 & & \\
\hline How is the strength of your current pain intensity from your shoulders? & 0.79 & & \\
\hline $\begin{array}{l}\text { Did you at any time during the last } 6 \text { months have absence due to sickness } \\
\text { because of inconveniences from the musculoskeletal systems? }\end{array}$ & 0.93 & Sick leave & 0.76 \\
\hline $\begin{array}{l}\text { Did you at any time during the last } 6 \text { months have absence due to sickness } \\
\text { because of psychosocial reasons? }\end{array}$ & 0.64 & & \\
\hline
\end{tabular}


Inter-correlations of the factors are presented in Table 2. Several factor correlations are significant, which is a precondition for a structural model analysis (Jöreskog and Sörbom 1993, Schreiber et al. 2006).

Table 2. Factor correlations in the confirmative analysis $(n=170)$.

Precision demands
Work posture
Social support
Psychosocial demands
Work control
Leadership
Work ability
Musculoskeletal disorders
Sick-leave

Sick-leave
A $\quad$ B

1.00

$0.36^{*} \quad 1.00$

$-0.06 \quad 0.00$

$0.22 * \quad 0.33^{*}$

$0.12 \quad 0.00$

$0.08-0.01$

$0.04 \quad 0.17 *$

$0.05 \quad 0.22 *$

$0.28 * \quad 0.20^{*}$

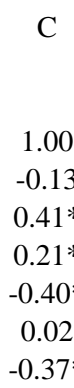

$\mathrm{D}$

E

$\mathrm{F}$

G

$\mathrm{H}$

I

$\mathrm{p}<0.05$.

\subsection{Statistical analyses}

\subsubsection{Changes during the study period}

Changes from 2003 to 2008 were evaluated by paired t-tests for related samples for the following factors: treatment time, precision demands, work posture, social support, psychosocial demands, work control, leadership, work ability, musculoskeletal disorders, sick-leave and productivity.

\subsubsection{Association patterns during the study period}

Structural Equation Modelling (SEM) was used to evaluate the structural associations between the factors describing working conditions, health and work ability and data for treatment times and productivity downloaded from the electronic patient register.

In an SEM analysis, it is possible to construct models where items can be both independent and dependent and which emerge during the process of creating the optimal model. According to Schreiber et al. (2006), SEM allows researchers to test theoretical propositions regarding how constructs are theoretically linked and the directionality of significant relationships. SEM 
combines the benefits of path analysis, factor analysis and multiple regression analysis and offers opportunities to measure factors among multiple manifest items and to statistically compare alternative hypothetical models. While most other multivariate procedures are descriptive, SEM takes a confirmatory approach to data analysis. In addition, traditional multivariate procedures are incapable of either assessing or correcting for measurement error. The SEM analysis is also suitable for evaluating the reciprocal direct and indirect relationships between the factors (Jöreskog and Sörbom, 1984, Tabachnick and Fidell, 1996).

The first SEM analysis shows the factors which have a significant effect in the hypothetical model and the factors which do not add any information to the hypothetical model. Several analyses were conducted where factors not adding any information were removed. Analyses were also conducted on the significant factors in different orders in relation to each other. Finally, when no further improvement was achieved in the analyses, the created model was considered to be optimal.

\subsubsection{Statistical software}

All statistical analyses and the explorative factor analyses were performed in SPSS, version 16 (SPSS Inc., Chicago, Ill., USA). The confirmative factor analyses and SEM analyses were carried out using the programs Analyses of Moment Structures, AMOS 17.0 (SPSS Inc., Chicago, Ill., USA) and LISREL 8.30 (Jöreskog and Sörbom, 1993). The results are presented as standardised regression weights (SRW).

\section{Results}

\subsection{Changes during the study period}

The number of treated adults increased from an average of 547 to 665 patients (28\%) per dentist ( $\mathrm{p}=0.02)$ while the number of treated children did not change during the study period 
(Table 3). However, the average treatment time per patient did not change significantly for neither adults nor children. The staff magazine, Munvädret (2009), reported that in 2003 15\% of adult patients failed to show up at the scheduled treatment time. In 2008, this had been reduced to 3\%. For children, about 3\% failed to appear for scheduled treatment in both 2003 and 2008.

The prevalence of neck symptoms was 65\% in 2003 and $70 \%$ in 2008 ( $p=0.3$ ), and the prevalence of shoulder symptoms was 52\% in 2003 and $61 \%$ in $2008(\mathrm{p}=0.7)$. About half of the dentists, 40\% in 2003 and 54\% in 2008, scored their physical and psychosocial work ability as "very good". In both 2003 and 2008, about 90\% expected to still be active in their profession two years after answering the questionnaire. A few (about 10\%) had been on sickleave due to musculoskeletal disorders or psychosocial reasons in 2003 and 2008.

Working conditions improved during the study period both in terms of precision demands $(\mathrm{p}<0.001)$ and work posture $(\mathrm{p}=0.001)$. Psychosocial working conditions showed a tendency to improve in terms of psychosocial demands $(\mathrm{p}=0.06)$, i.e. demands decreased, while perceived work control $(\mathrm{p}=0.01)$ and leadership $(\mathrm{p}=0.04)$ deteriorated during the study period (Table 3). 
Table 3. Average ratings (m), mean differences between 2003 and 2008 (Diff), probability (p), 95 percent confidence interval (CI95\%) for differences (Diff) for 65 dentists regarding productivity measure as well as different aspects of working conditions, health and work ability.

\begin{tabular}{|c|c|c|c|c|c|}
\hline & 2003 & 2008 & Diff & & Diff \\
\hline & $\mathrm{m}$ & $\mathrm{m}$ & $\mathrm{m}$ & $\mathrm{p}$ & $\begin{array}{c}\text { CI95\% } \\
\text { Lower-Upper }\end{array}$ \\
\hline \multicolumn{6}{|l|}{ Productivity } \\
\hline Treatment time, minutes, adults treated for a year per dentist ${ }^{3}$ & 34 & 33 & -1 & 0.6 & $2--4$ \\
\hline Treatment time, minutes, children treated for a year per dentist ${ }^{3}$ & 25 & 23 & -2 & 0,5 & $2--5$ \\
\hline Number of adults treated for a year per dentist ${ }^{3}$ & 547 & 665 & 118 & 0.02 & $215-20$ \\
\hline Number of children treated for a year per dentist ${ }^{3}$ & 446 & 477 & 31 & 0.4 & $110--47$ \\
\hline \multicolumn{6}{|l|}{ Working conditions } \\
\hline$(0=$ Not at all $-10=$ Greatly $)$ & 9.67 & 8.92 & -0.75 & $<0.001$ & $-0.59--0.91$ \\
\hline$(0=$ Not at all $-10=$ Greatly $)$ & 8.56 & 8.15 & -0.41 & 0.001 & $-0.14--0.68$ \\
\hline$(0=$ Not at all $-10=$ Greatly $)$ & 8.08 & 7.86 & -0.22 & 0.2 & $0.11--0.54$ \\
\hline Psychosocial demands $(0=$ Not at all $-10=$ Greatly $)$ & 7.36 & 6.97 & -0.39 & 0.06 & $0.02--0.82$ \\
\hline$(0=$ Not at all $-10=$ Greatly $)$ & 6.54 & 5.89 & -0.65 & 0.01 & $-0.20--1.09$ \\
\hline$(0=$ Poor $-10=$ Good $)$ & 6.60 & 6.18 & -0.42 & 0.04 & $-0.02--0.83$ \\
\hline \multicolumn{6}{|l|}{ Health and work ability } \\
\hline (Standardized) & - & - & - & 0.4 & - \\
\hline M.S. Disorders $^{2} \quad$ (Standardized) & - & - & - & 0.8 & - \\
\hline Sick-leave $(0=$ No sick leave $-5=$ Sick leave $>2$ months $)$ & 1.14 & 1.16 & 0.02 & 0.4 & $0.12--0,08$ \\
\hline
\end{tabular}

${ }^{1}$ Standardized: (Very good, -0.84 to 2.98 , Very poor 2003) and (Very good, -0.80 to 2.49, Very poor 2008). ${ }^{2}$ Standardized: (No disorders, -1.04 to 1.37, Great inconvenience 2003) and (No disorders, -1.25 to 1.48, Great inconvenience 2008).

\subsection{Association patterns during the study period}

The SEM analyses partly support the hypothetical model presented in Figure 1. In 2003, the two aspects of physical working conditions assessed as precision demands and work posture were associated (SRW: 0.57). Higher sick-leave was associated with lower work ability (SRW: -0.65) and these variables acted as intermediaries between physical working conditions and productivity. Increased work ability was associated with increased productivity (SRW: 0.57).

In 2008, after the rationalisations, the chain of associations remained similar but with other weights. The association between the two aspects of physical working conditions increased (SRW: 0.70), as did the negative association between work ability and productivity measures (SRW: -0.85). Treatment time entered the direct chain of associations as a mediator between 
work ability and production. Sick-leave and work ability also had a stronger direct association compared to 2003 (SRW: -0.87). The fit of the model is good (RMSEA=0.003 CFI=0.92 and RMR=0.09). Direct associations between the factors are presented as standardised regression weights (SRW), indicating the degree of change in standard deviation due to a factor and are shown in Figure 3.

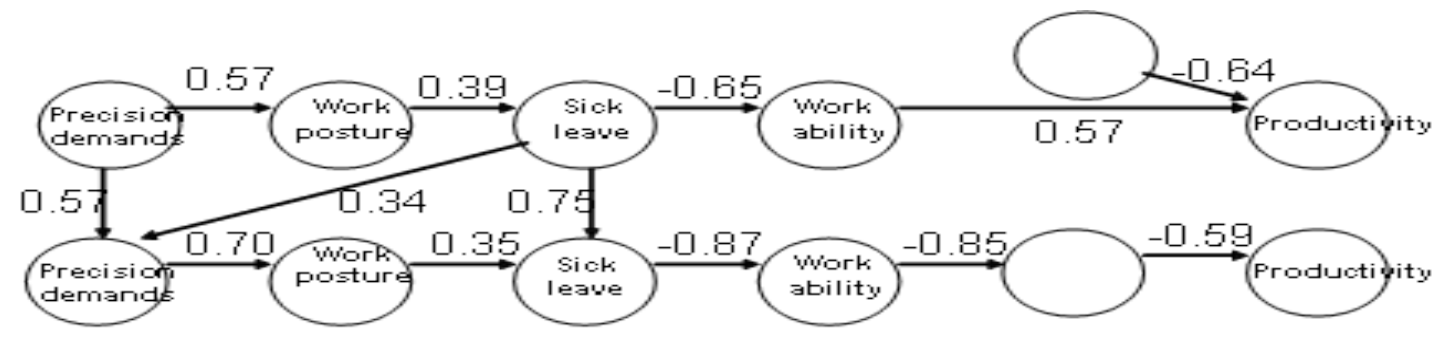

Figure 3. SEM testing associations between factors at two occasions; 2003 (upper line) and 2008 (lower line), and associations between the two occasions, with the hypothetical model (Figure 1) as a starting point. Only factors that fit the $S E M$ model are presented. Standardized regression weights (SRW) of direct effects are presented. RMSEA=0.00 CFI=0.92, and $R M R=0.09$. All indicated effects are significant $(p<0.05)$. The factor loadings of the 32 items or measures are excluded from the figure.

\section{Discussion}

During a 5-year period of rationalisations in Swedish public dental care, the perceived physical working conditions for dentists improved, while the psychosocial working conditions deteriorated in terms of the perceived quality of leadership and degree of control at work. The rationalisations led to increased productivity. The SEM analysis indicates the importance of physical conditions and that the significance of good health and work ability as mediators of productivity may have increased during the investigated period.

\subsection{Methodological considerations}

The obtained changes in outcome parameters from 2003 to 2008 may, potentially, be due to factors other than the introduced rationalisations. We have scrutinised local documents for such contextual factors and discussed the issue with local stakeholders. It has, however, not 
been possible to identify any such modifiers as potential alternative causes to the documented changes.

Bearing in mind the low number of participants $(n=65)$ and the complexity of the model, lower values of the fit indices in the SEM model were to be expected. One reason for the high values found is the clear and simple factor structure (i.e. generally high factor loadings). The reliable and valid factor structures found in a former study (Rolander and Bellner 2001) based on a large number of subjects formed a firm basis for performing the structural analyses. Another general reason is that the proposed model fits the empirical data to a high degree.

The response scales for physical working conditions had eleven positions with the anchor points labelled "Not at all" and "Greatly". The latter expression may have led to higher estimates with less dispersion, and the small difference in the high estimates may reduce the clinical significance (Kirkwood and Jonatan 2003) compared to a more powerful expression such as "worst case".

Another weakness is the use of an ordinal scale which means that the scale steps are not equal (equidistant). This contributes to increased uncertainty in determining the importance of changes and associations for the factors between 2003 and 2008 (Svensson 2001). However, it is inevitable that, in spite of the narrow dispersion, the different analyses generated various patterns with strong useful correlations. Productivity and rationalisation data were retrieved from the electronic patient register and were based on information reported yearly for 2003 and 2008. This type of data is collected for administrative purposes and, therefore, may be less precise compared to data collected for scientific purposes. Data may also suffer from confounding factors such as variation in types of absence which could affect productivity and ratings of exposures. Despite these weaknesses, the data is considered to be reliable because the pattern of changes and relationships observed in other factors seem to have good construct validity. 
The respondents were slightly older and had longer average working hours than dentist's in general public dental care in Jönköping. This suggests that our cohort was healthier because they were still in the profession despite many years as dentists, so called "healthy worker effect”, (Li and Sung 1999) which may have reduced variation in data.

\subsection{General Discussion}

\subsubsection{Impact of rationalisation}

Based on previous research, it was expected that rationalisation initiatives would impair physical and psychosocial working conditions (Westgaard and Winkel 2011). But, instead, this study shows perception of improved physical conditions, an improvement which is supported by longer periods of rest during work measured by inclinometers within the same group (Jonker et al, 2013). Previous studies of dentists have shown high physical exposures (Akesson et al. 1997, Finsen et al. 1998, Rolander et al. 2005a, Rolander et al. 2005b, Jonker et al. 2009), possibly due to years of Tayloristic rationalisations (Winkel and Westgaard 1996). Thus, the most recent years of rationalisation primarily now seem to affect the psychosocial working environment negatively, thus emphasising the need to focus on management style and dentist involvement in future interventions. The perception of improved physical working environment was unexpected during the present period of rationalisation (cf. Westgaard and Winkel 2011), in particular due to the increased performance by the dentists. This may be related to changes in task allocation between the different occupational groups. However, this issue needs further investigation.

Our study partially confirms previous studies which show that the perception of poor leadership during rationalisation may impair aspects of the psychosocial working environment 
(reduced work control) (e.g. Bejerot et al. 1998, 1999). Recent studies by Berthelsen et al. (2011) emphasise the importance of managing dentistry in a way that respects the professional values of dentists. This seems not to have been fulfilled by at least some aspects of the present investigated rationalisations. Decisions that are comprehensive in nature, such as the digitisation of medical records or the delegation of tasks to other professions, are decisions made by the management, while the dentists still have the main responsibility for the medical results (SOU 2002). The increased specialisation and delegation of some tasks to other professions may heighten the experience of less control. A lack of work control has, in a number of studies, been shown to be a core dimension of job stress and may, in a longer perspective, contribute to ill health (Karasek and Theorell 1990, Lavoie-Tremblay et al. 2008, Roquelaure et al. 2009).

\subsubsection{Changes in association patterns (cf. Figure 1)}

Treatment time became a direct measure with a greater impact on productivity in 2008 compared to 2003, although the average treatment time per patient did not change significantly. The introduction of SMS text message reminders increased patient attendance, thereby improving predictability. However, it also caused higher patient flow, presuming reduced work porosity (i.e. rest allowance) for the dentists. The staff magazine states that the introduction of SMS text message reminders in 2005 resulted in cost reductions of SEK 7.1 million (USD 1 million, approx. 4, 9\% of the total income from public dental care) for missed patient visits compared with 2004. (Munvädret 2009:3). Unfortunately, the link between the introduction of SMS text message reminders and economic improvement is not described and conclusions can, therefore, only be tentative. Nonetheless, several studies show that technical changes seem to improve productivity (Baltutis and Morgan 1998, Anderson 2004, Widstrom et al. 2004, Aldridge 2006). In general, reorganisation aims to improve effectiveness and 
reduce costs by, for example, eliminating waiting times for staff and improving work processes (Abelsen and Olsen 2008).

In this study, physical working conditions were stronger determinants for health, work ability and productivity, compared to psychosocial factors which did not fit into the optimal models. It is, however, important to note that the psychosocial work environment is relevant to health and work ability (Bejerot 1998, Hjalmers et al. 2006, Rolander et al. 2008). Several studies show that organisational change may lead to perceived stressful work conditions, affecting sick-leave, health and work ability (Kivimaki et al. 1997, Vahtera et al. 2000, Alexandersson and Norlund 2004, Ferrie et al. 2005, Voss et al. 2008). Poor control and leadership support may increase the risk for future health problems and reduced productivity (Bejerot et al. 2011) as indicated by the greater impact of health and work ability on productivity after rationalisations in 2008.

\section{Conclusion}

The present investigation suggests, in contrast to previous research, that a sample of rationalisation interventions in Swedish public dental care managed to improve productivity and, at the same time, also improve perceived physical working conditions. However, in line with previous research assessments, the perception of work control and leadership was impaired. The effects of rationalisation on production were mediated mainly by the effects of physical working conditions on health and perceived work ability. This suggests that when assessing risks in the work environment, is it important to analyse both the changes and the association patterns between exposures, health and production.

Thus, the present investigation represents a system approach focusing both performance and well-being. In a recent position paper by Dul et al (2012) these issues have been suggested as key elements that need to be strengthened in future Human Factors/Ergonomics. 


\section{References}

Abelsen, B. \& Olsen, J.A., 2008. Task division between dentists and dental hygienists in Norway. Community Dent Oral Epidemiol, 36 (6), 558-66.

Akesson, I., Hansson, G.A., Balogh, I., Moritz, U. \& Skerfving, S., 1997. Quantifying work load in neck, shoulders and wrists in female dentists. Int Arch Occup Environ Health, 69 (6), 461-74.

Akesson, I., Johnsson, B., Rylander, L., Moritz, U. \& Skerfving, S., 1999. Musculoskeletal disorders among female dental personnel - clinical examination and a 5-year follow-up study of symptoms. Int Arch Occup Environ Health, 72 (6), 395-403.

Aldridge, D., 2006. Improved patient education and practice efficiency via digital radiography - part i. Pract Proced Aesthet Dent, 18 (4), 212, 214.

Alexandersson, K. \& Norlund, A., 2004. Sick-listing - causes, consequences, and practice. Scand J Public Health, 63, 6-11.

Alexopoulos, E.C., Stathi, I.C. \& Charizani, F., 2004. Prevalence of musculoskeletal disorders in dentists. BMC Musculoskelet Disord, 5, 16.

Almqvist, R., 2006. Management by contract - a study of programmatic and technological aspects. Public Administration - an international quarterly, 79 (3), 689-706.

Anderson, L.H., 2004. Integrated office technology: How technology can help improve office efficiency. J Am Dent Assoc, 135 Suppl, 18S-22S.

Baltutis, L. \& Morgan, M., 1998. The changing role of dental auxiliaries: A literature review. Aust Dent J, 43 (5), 354-8.

Bejerot, E., Soderfeldt, B., Aronsson, G., Harenstam, A., Soderfeldt, M., 1999. Perceived control systems, work conditions, and efficiency among Swedish dentists: interaction between two sides of Human Resource Management. Acta Odontologica Scandinavica $57,46-54$

Bejerot, E., Soderfeldt, B., Aronsson, G., Harenstam, A. \& Soderfeldt, M., 1998. Changes in control systems assessed by publicly employed dentists in comparison with other professionals. Acta Odontol Scand, 56 (1), 30-5.

Bejerot, E., Aronsson, G., Ibladh, H, \& Bejerot, S., 2011. Läkarkåren en profession med allt mindre stöd och inflytande. Läkartidningen, 108(50), 2562-2655. (English abstract).

Bjorkman, T., 1996. The rationalisation movement in perspective and some ergonomic implications. Appl Ergon, 27 (2), 111-7.

Brödner, P. \& Forslin, J. eds. 2002. O tempora, o mores! Work intensity - why again an issue?, London: Taylor \& Francis.

Byrne, B.M., 2001. Structural equation modeling with amos Mahtwah, New Jersey: Lawrence Erlbaum Associates Inc.

Dul, J.,Bruder, R.,Buckle, P.,Carayon, P.,Falzon, P.,Marras,W, S.,Wilson, J, R \& Bas van der Doelen.,2012. A strategy for human factors/ergonomics: developing the discipline and profession. Ergonomics, 55 (4), 377-95.

Ekberg, K., Bjorkqvist, B., Malm, P., Bjerre-Kiely, B., Karlsson, M. \& Axelson, O., 1994. Case-control study of risk factors for disease in the neck and shoulder area. Occup Environ Med, 51 (4), 262-6.

Ferrie, J.E., Kivimaki, M., Head, J., Shipley, M.J., Vahtera, J. \& Marmot, M.G., 2005. A comparison of self-reported sickness absence with absences recorded in employers' registers: Evidence from the Whitehall II study. Occup Environ Med, 62 (2), 74-9.

Finsen, L., Christensen, H. \& Bakke, M., 1998. Musculoskeletal disorders among dentists and variation in dental work. Appl Ergon, 29 (2), 119-25. 
Forsman, M., Hansson, G.A., Medbo, L., Asterland, P. \& Engstrom, T., 2002. A method for evaluation of manual work using synchronised video recordings and physiological measurements. Applied Ergonomics, 33, 533-540.

Harrisson, S., Hunter, D.J. \& Pollit, C., 1990. The dynamics of British health policy: Unwin Hyman Ltd. London

Hasselbladh, H., 2001. Staten och managementrörelserna. Kommunal ekonomi och politik, 5 (2), 9-29.

Hjalmers, K., Soderfeldt, B. \& Axtelius, B., 2006. Moral values and career: Factors shaping the image of healthy work for female dentists. Acta Odontol Scand, 64 (5), 255-61.

Jonker, D., Rolander, B. \& Balogh, I., 2009. Relation between perceived and measured workload obtained by long-term inclinometry among dentists. Appl Ergon, 40 (3), 309-15.

Jonker, D., Rolander, B., Balogh, I., Sandsjö, L., Ekberg, K. \& Winkel, J., 2011. Mechanical exposure among general practice dentists in Sweden and possible implications of rationalisation. Ergonomics, 54 (10), 953-60.

Jonker, D., Rolander, B., Balogh, I., Sandsjö, L., Ekberg, K. \& Winkel, J., 2013. Rationalisation in public dental care - impact on clinical work tasks and mechanical exposure for dentists - a prospective study. Ergonomics, 56:2, 303-13.

Jöreskog, K.G. \& Sörbom, D., 1993. Structural equation modeling with the simplis command language. Hillsdale: Lawrence Erlbaum Associates, Inc.

Karasek, R. \& Theorell, T., 1990. Healthy work - stress, productivity and the reconstruction of working life. New York: Basic Books.

Kazmierczak, K., Mathiassen, S.E., Forsman, M. \& Winkel, J., 2005. An integrated analysis of ergonomics and time consumption in Swedish 'craft-type' car disassembly. Appl Ergon, 36 (3), 263-73.

Kirkwood, B.R. \& Jonatan, A.C.S., 2003. Medical statistics. Oxford.

Kivimaki, M., Vahtera, J., Thomson, L., Griffiths, A., Cox, T. \& Pentti, J., 1997. Psychosocial factors predicting employee sickness absence during economic decline. J Appl Psychol, 82 (6), 858-72.

Kuorinka, I., Jonsson, B., Kilbom, A., Vinterberg, H., Biering-Sorensen, F., Andersson, G. \& Jorgensen, K., 1987. Standardised nordic questionnaires for the analysis of musculoskeletal symptoms. Appl Ergon, 18 (3), 233-7.

Landsbergis, P.A., Cahill, J. \& Schnall, P., 1999. The impact of lean production and related new systems of work organization on worker health. J Occup Health Psychol, 4 (2), 108-30.

Lavoie-Tremblay, M., Wright, D., Desforges, N., Gelinas, C., Marchionni, C. \& Drevniok, U., 2008. Creating a healthy workplace for new-generation nurses. Journal of Nursing Scholarship, 40 (3), 290-297.

Leggat, P.A., Kedjarune, U. \& Smith, D.R., 2007. Occupational health problems in modern dentistry: A review. Ind Health, 45 (5), 611-21.

Li, C.Y. \& Sung, F.C., 1999. A review of the healthy worker effect in occupational epidemiology. Occup Med (Lond), 49 (4), 225-9.

McCann, L., Morris, J. \& Hassard, J., 2008. Normalized intensity: The new labour process of middle management. Journal of Management Studies, 45, 343-371.

Munvädret, 2003:2. Jönköping County Council's public company dental newsletter. In Swedish.

Munvädret, 2003:3. Jönköping County Council's public company dental newsletter. In Swedish.

Munvädret, 2009:3. Jönköping County Council's public company dental newsletter. In Swedish. 
Ostensvik, T., Veiersted, K.B., Cuchet, E., Nilsen, P., Hanse, J.J., Carlzon, C. \& Winkel, J., 2008. A search for risk factors of upper extremity disorders among forest machine operators: A comparison between France and Norway. International Journal of Industrial Ergonomics, 38, 1017-1027.

Palmerud G, Forsman M, Neumann P W, Winkel J., 2012. Mechanical exposure implications of rationalization: impacts of flow strategy and work intensification. Applied Ergonomics, 43, 1110-1121.

Rolander, B. \& Bellner, A.L., 2001. Experience of musculo-skeletal disorders, intensity of pain, and general conditions in work - the case of employees in non-private dental clinics in a county in southern Sweden. Work, 17 (1), 65-73.

Rolander, B., Jonker, D., Karsznia, A. \& Oberg, T., 2005a. Evaluation of muscular activity, local muscular fatigue, and muscular rest patterns among dentists. Acta Odontol Scand, 63 (4), 189-95.

Rolander, B., Karsznia, A., Jonker, D., Oberg, T. \& Bellner, A.L., 2005b. Perceived contra observed physical work load in Swedish dentists. Work, 25 (3), 253-62.

Rolander, B., Stenstrom, U. \& Jonker, D., 2008. Relationships between psychosocial work environmental factors, personality, physical work demands and workload in a group of Swedish dentists. Swed Dent J, 32 (4), 197-203.

Roquelaure, Y., Ha, C., Gohier, B., Dano, C., Touranchet, A., Leclerc, A., Imbernon, E. \& Goldberg, M., 2009. Exposure to psychosocial stressors at work in the Pays de la Loire region in 2002. L'Encephale, 33 (2), 160-168.

Schreiber, J.B., Stage, F.K., King, J.,Nora, A., Barlow, E.A., 2006. Reporting structural equation modeling and confirmatory factor analysis: A Review. Journal of Educational Research, 99(2), 323-337.

Seppälä, P., 2004. Flat organizations and the role of white-collar employees in production. International Journal of Industrial Ergonomics, 33, 15-27.

SOFS, 1997:14. Swedish national public investigations

Sou, 2002. Swedish national public investigations.

Svensson, E., 2001. Guidelines to statistical evaluation of data from rating scales and questionnaires. J Rehabil Med, 33 (1), 47-8.

Tabachnik, B.G., Fidell, L.S, 1996. Using multivariate statistics New York: Harper Collins

Tuomi, K., Ilmarinen, J., Jahkola, A., Katajarinne, L. \& Tulkki, A. eds. 1998. Work ability index 2nd revised edn Finnish Institute of Occupational Health, Helsinki.

Vahtera, J., Kivimaki, M., Pentti, J. \& Theorell, T., 2000. Effect of change in the psychosocial work environment on sickness absence: A seven year follow up of initially healthy employees. J Epidemiol Community Health, 54 (7), 484-93.

Vest, J.R. \& Gamm, L.D., 2009. A critical review of the research literature on Six Sigma, Lean and StuderGroup's Hardwiring Excellence in the United States: The need to demonstrate and communicate the effectiveness of transformation strategies in healthcare. Implementation Science, 4:35.

Westgaard, R.H. \& Winkel, J., 2011. Occupational musculoskeletal and mental health: Significance of rationalization and opportunities to create sustainable production systems - a systematic review. Appl Ergon, 42 (2), 261-96.

Widstrom, E., Linna, M. \& Niskanen, T., 2004. Productive efficiency and its determinants in the Finnish public dental service. Community Dent Oral Epidemiol, 32 (1), 31-40.

Winkel, J. \& Westgaard, R.H., 1996. A model for solving work related musculoskeletal problems in a profitable way. Appl Ergon, 27 (2), 71-7.

Voss, M., Stark, S., Alfredsson, L., Vingard, E. \& Josephson, M., 2008. Comparisons of selfreported and register data on sickness absence among public employees in Sweden. Occup Environ Med, 65 (1), 61-7. 
